\title{
Challenges in the Development of Film-Forming Additives for Lithium Ion Battery: A Review
}

\author{
Yannan Zhang ${ }^{1}$, Yingjie Zhang ${ }^{1}$, Shubiao Xia ${ }^{1}$, Peng Dong ${ }^{1}$, Liying $\mathrm{Jin}^{2}$, Jinjie Song ${ }^{3}$ \\ ${ }^{1}$ Faculty of Materials Science and Engineering, Kunming University of Science and Technology, Kunming, China \\ ${ }^{2}$ Shandong Institute of Physical Education and Sports, Jinan, China \\ ${ }^{3}$ Key Laboratory of Mesoscale Severe Weather/MOE, School of Atmospheric Sciences, Nanjing University, Nanjing, China \\ Email: zyn_legolas@163.com
}

Received April 12, 2013; revised May 21, 2013; accepted June 5, 2013

Copyright (C) 2013 Yannan Zhang et al. This is an open access article distributed under the Creative Commons Attribution License, which permits unrestricted use, distribution, and reproduction in any medium, provided the original work is properly cited.

\begin{abstract}
Electrolytes additives are ubiquitous and indispensable in all electrochemical devices. In this sense, the principle and the classification of film-forming additives for lithium ion secondary batteries are described. The film formation mechanism and research progress of the pyrazole derivatives, organic halogenide, esters and derivatives, boron compounds and inorganic compounds are introduced. Emphasis is focused on the principles and film-forming mechanisms of each additive. The development of film-forming additives is forecasted and prospected.
\end{abstract}

Keywords: Lithium Ion Battery; Film-Forming Additives; Solid Electrolyte Interphase Film

\section{Introduction}

In recent years, the lithium ion battery has been used in various electric devices owing to its large energy density, light volume, excellent cycle performance and no memory effect [1]. Conventionally, a passivation layer-solid electrolyte interphase film has been formed on the cathode surface in the case of lithium ion battery charging and discharging during the first cycle, which could effectively distinguish between the electrolyte and cathode materials. The lithium is a poor conductor of ions whereas it is a good conductor of electronics [2,3]. The film inhibits the continuous consumption of lithium and plays an important role in the protection of electrode $[4,5]$. Some studies have shown that, for the electrochemical performance of battery, it is critical to understand whether a layer of film with uniform, stable, low impedance and excellent adhesion properties can be formed [6-8]. More importantly, the layer consumes lithium irreversibly on the initial charge of a Li-ion cell, which robs the capacity from the cathode, unless the SEI layer is preformed before the cell assembly [7-9]. Therefore, it is of great academic and practical significance to develop the film-forming additives so that the main ingredients of the electrolyte solvent are preferentially decomposed into the uniform and stable SEI film on the graphite negative electrode materials.

\section{Mechanism of the Film-Forming Additives}

According to Peled's model, the SEI forms instantane- ously upon its contact with electrolytes for the lithium metal, and the reduction of electrolyte components should be indiscriminate to all possible species. On the other hand, the formation of the SEI should be a stepwise and preferential reduction of certain electrolyte components on the anode. The existence of an SEI constitutes the foundation on which lithium ion chemistry could operate reversibly. Inside the lithium batteries, the initial step of electrochemical reduction is characterized by one electron transmitting from the electrode with anode polarization to the solvation of the lithium ion battery. Then free radicals of solvent molecules establish the charge exchange balance with complexing solvent molecules. It has also been realized that this formation process does not start until the potential of potential of carbonaceous anodes being cathodically polarized to a certain level [1013]. Aurbach et al. [14] found that the electron-withdrawing ability of the reactive group is a critical factor for SEI formation. The reactive groups could restrain the destruction of the graphite anode from solvent molecules, and inhibit the excessive decomposition of electrolyte components so as to passivate the electrode surface effectively.

The chemical software calculation may be a good method to screen film-forming additives. On the basis of molecular orbital theory, the energies of the highest occupied molecular orbital (HOMO) and lowest unoccupied molecular orbital (LUMO) determine the ability of 
molecules to lose and gain electrons $[15,16]$. Kito et al. [17] used LUMO, HOMO energy level to estimate the oxidation stability for some additives. Johansson [18] selected an initio quantum mechanical calculations as the primary selection and search toll in the quest for new lithium salts.

\section{Classification of the Film-Forming Additives}

Based on the existence of room temperatures, can be divided into gas, liquid and solid film-forming additives. Meanwhile, considering on the film forming mechanisms, can be divided into reduction, reaction and modification additives. Besides these classifications, on the molecular structure, can be divided into ring and chain based on the molecular structures.

\subsection{Pyrazole Derivatives and Organic Halogenide Additives}

Without exceptions, more electroactive the molecules, easier formation of SEI film under high negative electrode potential [19]. For the same type of organic solvent, when the alkyl volume is greater, the oxygen density of electron cloud is higher and the molecular is less active. It indicates that the compound with strong electron-withdrawing has a good application in the film and thermal stabilized additives, such as pyrazole derivatives and organic halogenide compounds [20,21].

Abouimrace et al. [22] added 3-hexylthiophene to a 1.2 M LiPF6 EC/EMC (3/7) electrolyte solution in amounts varied from $0.05 \mathrm{wt} \%$ to $0.20 \mathrm{wt} \%$. Upon oxidation, this monomer forms a conductive, conjugated polymer on the cathode surface resulting in significant increase in the cycle lifetimes of lithium half-cells containing high capacity $\mathrm{Li}_{1.2} \mathrm{Ni}_{0.15} \mathrm{Co}_{0.1} \mathrm{Mn}_{0.55} \mathrm{O}_{2}$ and high voltage $\mathrm{LiNi}_{0.5} \mathrm{Mn}_{1.5} \mathrm{O}_{4}$ cathodes [23].

Dawoong et al. [24] used 3-(trifluoromethyl) pyrazole (TFMP), Pyrazole, 3,5-bis(trifluoromethyl) pyrazole (BTFMP) as functional electrolytes, and added them into $1.1 \mathrm{M} \mathrm{LiPF}_{6}$ with $\mathrm{EC} / \mathrm{EMC}$ equaling to $4: 6$ by volume. The linear sweep voltammogram curves show that the pyrazole and BFTMP are easier to oxidize than the TFMP. The energy required to remove the film satisfies that: no-additive $<$ TFMP $<$ pyrazole $<$ BTFMP. The formation of passivation films can prohibit further rapid electrolysis of electrolytes, while high intensity of the oxidative current can assist in creating thicker or denser films on the electrodes. That's the reason that pyrazole derivatives show excellent properties as thermal protectors and film-forming additives.

Chen et al. [25] synthesized allyl tris(2,2,2-trifluoroethyl) carbonate (ATFEC) and used it as a bi-functional additive in electrolytes for lithium ion batteries. Figure 1

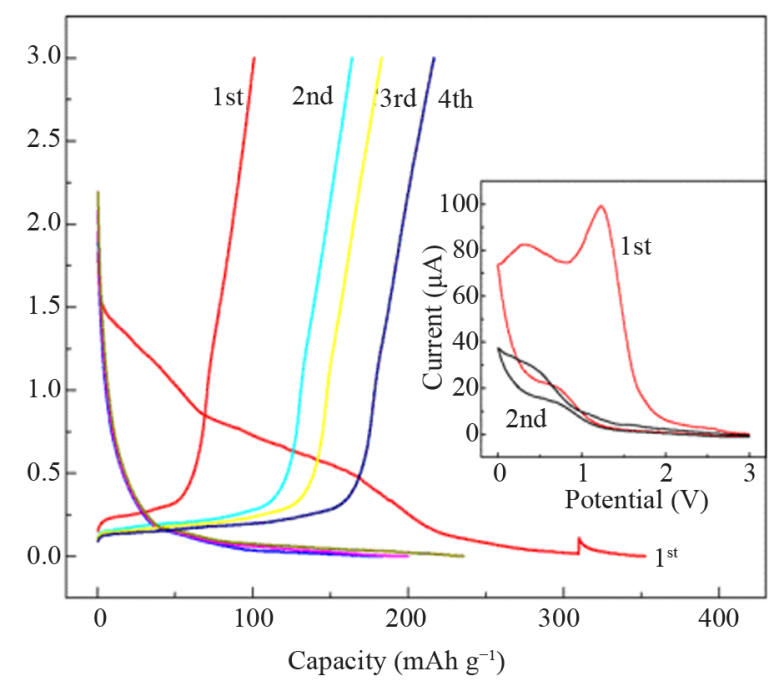

Figure 1. The voltage profiles of a $\mathrm{Li} / \mathrm{NG}$ cell in the first four cycles using $1 \mathrm{M} \mathrm{LiPF}_{6} / \mathrm{PC}+1$ vol.\% ATFEC electrolyte and cycled at a current density of $0.1 \mathrm{~mA} \cdot \mathrm{cm}^{-2}$ between 0 and 3.0 $\mathrm{V}$ vs $\mathrm{Li}$. The inset is for the cyclic voltammograms of a three-electrode $\mathrm{Li} / \mathrm{NG}$ cell using the same electrolyte in the first two cycles at a scan rate of $0.1 \mathrm{mV} \cdot \mathrm{s}^{-1}[25]$.

shows that the film-forming effect of 1\% ATFEC on natural graphite in $1 \mathrm{M} \mathrm{LiPF}_{6} / \mathrm{PC}$ electrolyte. The potential plateau at around $1.2 \mathrm{~V} \mathrm{vs} \mathrm{Li}$. in the first discharge is ascribed to the decomposition of ATFEC. The coulombic efficiency of the cell is only $29 \%$ in the first cycle. And in the subsequent cycles the efficiency continuously rises with the increasing thickness and compactness of the SEI layer as a decomposition product of the additive. The coulombic efficiency of the cell increases to $92 \%$ after four cycles. This means that the formed SEI layer is stable and effective in preventing the co-intercalation of PC. And the flame-retarding effect of the ATFEC additive in the electrolytes reveals that the SET of the electrolyte decreases from $65 \mathrm{sg}^{-1}$ for the original electrolyte to 18 $\mathrm{sg}^{-1}$ when 30 vol.\% ATFEC is added. It indicates that addition of ATFEC can enhance the thermal stability and shorten the flame extinguishing time of the electrolyte significantly.

\subsection{Esters and Derivatives}

Wu et al. [26] prepared a new binary electrolyte containing tetramethylene sulfone (TMS) and hexamethylene diisocyanate (HDI) with lithium difluoro(oxalate)botate (LiODFB) as the lithium salt. Combined with the mixed electrolyte, $\mathrm{LiNi}_{1 / 3} \mathrm{Co}_{1 / 3} \mathrm{Mn}_{1 / 3} \mathrm{O}_{2}$ and $\mathrm{LiCoO}_{2}$ cathode materials show specific capacities of nearly $168.3 \mathrm{~mA} \mathrm{~h} \cdot \mathrm{g}^{-1}$ and $134.5 \mathrm{~mA} \mathrm{~h} \cdot \mathrm{g}^{-1}$ after 50 cycles, respectively, which is superior to those containing the traditional electrolyte. The frontier molecular orbitals of various electrolytes and their energies were calculated and are shown in Figure 2. The energy of the HOMO of HDI and EI is lower 
(a)

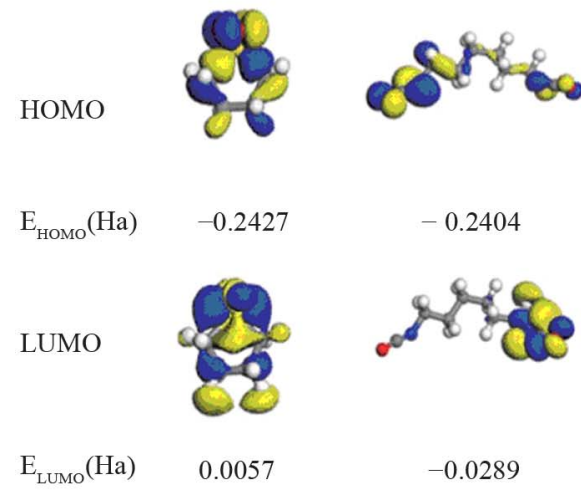

EI

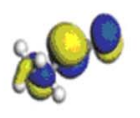

$-0.2405$

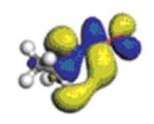

$-0.0233$
BI

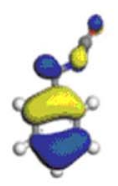

$-0.2192$

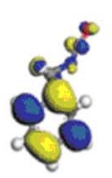

$-0.0433$
PTI

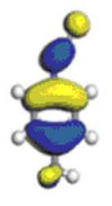

$-0.2036$

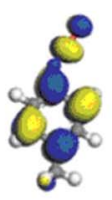

$-0.0528$
FPI

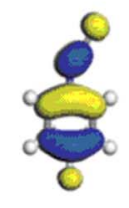

$-0.2138$

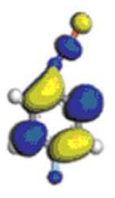

$-0.0627$

Figure 2. Frontier molecular orbitals and energies of TMS and various isocyanate compounds [26].

than that of other isocyanate compounds, while the energy of their LUMO is higher, the existence of fluorine is indicative of a low energy HOMO of the compound molecule, and this raises its oxidation potential. This can be explained why HDI has a high oxidation potential $(5.2 \mathrm{~V})$ and an outstanding ability to form an SEI layer.

Han et al. [27] added a small amount (3 wt\%) of succinic anhydride (SA) into the liquid electrolyte in order to improve the electrochemical performance of amorphous Si thin film electrode during cycles without sacrificing the charge-discharge potential. The presence of SA can prevent the decomposition of the $\mathrm{LiPF}_{6}$ salt on the $\mathrm{Si}$ surface on which an SEI layer with higher hydrocarbon and $\mathrm{Li}_{2} \mathrm{CO}_{3}$ contents is formed. This is explained by scanning electron micrographs and XPS spectra for Si thinfilm electrodes. It appears to be the primary factor of a proper SEI layer enhancing the interfacial properties of the Si surface.

In a recent report, vinylene carbonate (VC) might be the most famous in the lithium ion research and development community $[28,29]$. The small concentration of $\mathrm{VC}$ can effectively reduce the irresversible capacity associated with the $0.80 \mathrm{~V}$ process in almost any PC-based electrolyte, $\mathrm{VC}$ in the bulk concentration, does not constitute any instability on the charged surface of anode materials [30]. Aurbach et al. [31] chose VC as an additive to electrolyte solutions for the model electroldes, synthetic graphite as the anode material, and $\mathrm{LiMn}_{2} \mathrm{O}_{4}$ spinel and $\mathrm{LiNiO}_{2}$ as the cathode materials. The spectroscopic studies indicate that $\mathrm{VC}$ is reduced to the species containing $\mathrm{OCO}_{2} \mathrm{Li}$ groups that have $\mathrm{C} \mathrm{C}$ double bonds on graphite electrodes at low potential in EC-containing solutions. The presence of $\mathrm{VC}$ in $\mathrm{EC}-\mathrm{DMC} / \mathrm{LiPF}_{6}$ solutions reduces the irreversible capacity of lithiated graphite electrodes and improves their stability during prolonged cycles, especially at elevated temperature. Shu et al. [32] added chloroethylene carbonate into non aqueous electrolyte for a graphite anode and noticed that the elec- trolyte decomposition during the first lithium intercalation into graphite in a ropylene carbonate based electrolytes is significantly reduced under the presence of chloroethylene carbonate. Formation of a stable passivation film on the graphite surface is believed to be the reason for the improved cell performance.

Xie et al. [33] tested the effect of gamma-crotonlatione (GCL) to electrolyte solutions of $1 \mathrm{M} \mathrm{LiPF}_{6}$ EC:DMC $(1: 1, \mathrm{vol})$. The result indicates that the lithium ion battery with electrolyte containing GCL has excellent low temperature electrochemical behaviors, and can operate at $-60^{\circ} \mathrm{C}$. Cyclic volatammetry shows that the GCL has higher reduction decomposition potential at about $2.1 \mathrm{~V}$. Charge-discharge test explains that smaller volume amounts in the order of $10^{-6} \mathrm{GCL}$ can efficiently improve the cyclic performance of MCMB electrode and decrease the impedance of MCMB/Li half-cell. FTIR and XPS reveal that the SEI film derived from GCL is less element $(\mathrm{P}, \mathrm{F})$ components, and more $\mathrm{Li}_{2} \mathrm{CO}_{3}$ than that derived from the electrolyte without GCL as shown in Figure 3.

\subsection{Boron Compounds}

Since the bis(oxalate)borate ( $\mathrm{LiBOB}$ ) was disclosed by Lischka et al. [34], a series of studies of its properties have been carried on. It meets the basic requirements for a salt to be used in lithium-ion cell: good thermal stability, wide electrochemical window, acceptable conductivity at ambient temperature, and the ability to form SEI layer on the electrodes and to passivate aluminum current collector from anodic dissolution $[35,36]$. The two unique properties of $\mathrm{LiBOB}$ were identified by and $\mathrm{Xu}$ and co-workers: 1) the ability of the LiBOB-containing lithium ion cells with lithium nickel-based mixedmetal oxide cathode cycle at elevated temperatures [36] and 2) the ability of LiBOB to effectively stabilize the grapheme structure even in neat $\mathrm{PC}$ solution. Unlike $\mathrm{LiPF}_{6}$ decomposing to $\mathrm{LiF}$ and $\mathrm{PF}_{5}$ at high temperature $\mathrm{LiBOB}$ is 


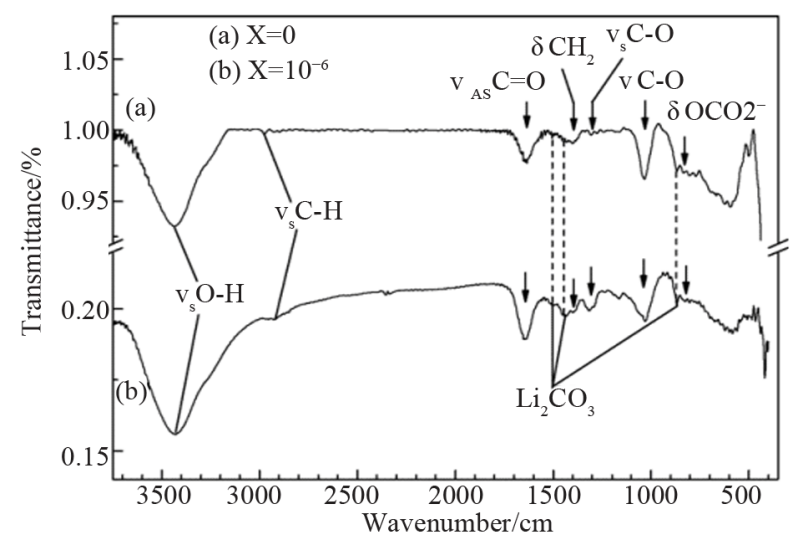

Figure 3. The FTIR spectra of MCMB electrodes cycled in different EC-based electrolytes: (a) without GCL; (b) with GCL [33].

stable below $302^{\circ} \mathrm{C}$. This unique property is regarded to solve capacity fading of $\mathrm{LiMn}_{2} \mathrm{O}_{4}$ spinel cathode cycling at higher temperatures [37]. Tang et al. [38] also investigated the formation of the SEI film on graphite in a LiBOB-based electrolyte by EIS, XPS and FTIR. The effects of the SEI film on the cycle abilities of graphite were examined at $25^{\circ} \mathrm{C}$ and $70^{\circ} \mathrm{C}$. Results show that the SEI film is formed at around $1.7 \mathrm{~V}$. And BOB-ions are reduced to oxalate, which is one of the components of the SEI film. Meanwhile, the graphite has better cycleability in the LiBOB-based electrolyte than that in the $\mathrm{LiPF}_{6}$ Based electrolyte no matter what temperature is at room.

\subsection{Inorganic Compounds}

Aurbach et al. [39] noticed that the presence of $\mathrm{CO}_{2}$ in the electrolyte had pronounced effects on the lithiation behavior of graphitic anodes and proposed that $\mathrm{CO}_{2}$ participated in the formation of the SEI by two-electon process, yielding $\mathrm{Li}_{2} \mathrm{CO}_{3}$, which assisted in the buildup of the protective surface. Osake et al. [40] tried to inject some small molecules $\left(\mathrm{CO}_{2}, \mathrm{SO}_{2}\right)$ into organic electrolyte and noticed that all of them can accelerate the formation of passive film. Besides $\mathrm{CO}_{2}$ and $\mathrm{SO}_{2}$, other gaseous in an inorganic salt species such as $\mathrm{N}_{2} \mathrm{O}$ [41], $\mathrm{Li}_{2} \mathrm{CO}_{3}$ [42], $\mathrm{Li}_{2} \mathrm{SO}_{3}$, and $\mathrm{K}_{2} \mathrm{CO}_{3}$ [43] are also considered as additives. Jee et al. [42] examined the generated gases and passive films on the carbon electrode by chromatography and Fourier transformed infrared spectroscopy. When 0.05 $\mathrm{Li}_{2} \mathrm{CO}_{3}$ is added as an electrolyte additive, the total volume of generated gases is reduced, and the discharge capacity and the conductivity of lithium-ions are increased. These results can be explained by the genesis of more compact and thin SEI film on the carbon electrode formed by $\mathrm{Li}_{2} \mathrm{CO}_{3}$. Zheng et al. [43] found that the presence of $\mathrm{K}_{2} \mathrm{CO}_{3}$ in the electrolyte prior to the charge-discharge cycle considerably reduced the irreversible capacity loss in the first cycle, which was attributed to the mild electrolyte reduction at the electrode/electrolyte interface resulting in the formation of a thin, homogenous, and more conductive soli electrolyte interface on the graphite surface.

\section{Conclusion}

In conclusion, the efficient and stable SEI film formation is crucial to the cycle performance and capacity of lithium-ion batteries. On the other hand, a reasonable use of the additives could significantly change the targeted property.

The current trend of developing film-forming additives is: 1) less adverse reactions to the cycling of $\mathrm{Li}$ ions; 2) additive-combination for developing additives with a high reductive decomposition potential and good reversibility such as using PC combined with PS to improve the stability of the solution; 3 ) chemical software calculation and molecular designment serving as a good method to screen film-forming additives; 4) research on solid electrolyte with a high ion conductivity at room temperature, good phase and chemical stability which is also an important direction of film-forming additives.

\section{REFERENCES}

[1] N. Kamaya, K. Homma, Y. Yamakawa, et al., "A Lithium Superionic Conductor," Nature, Vol. 31, No. 10, 2011, pp. 682-686. doi:10.1038/nmat3066

[2] P. Verma, P. Maire and P. Novák, "A Review of the Features and Analyses of the Solid Electrolyte Interphase in Li-Ion Batteries," Electrochim Acta, Vol. 55, No. 22, 2010, pp. 6332-6341. doi:10.1016/j.electacta.2010.05.072

[3] S. H. Fang, Y. F. Tang, X. Y. Tai, et al., "One Ether-Functionalized Guanidinium Ionic Liquid as New Electrolyte for Lithium Battery," Journal of Power Sources, Vol. 196, No. 3, 2011, pp. 1433-1441. doi:10.1016/j.jpowsour.2010.08.012

[4] N. Shao, X. G. Sun, S. Dai, et al., "Oxidation Potentials of Functionalized Sulfone Solvents for High-Voltage LiIon Batteries: A Computational Study," Journal of Physical Chemistry B, Vol. 116, No. 10, 2012, pp. 3235-3238. doi:10.1021/jp211619y

[5] E.-G. Shim, T.-H. Ham, J.-G. Kim, et al., "Effects of Functional Electrolyte Additives for Li-Ion Batteries," Journal of Power Sources, Vol. 172, No. 2, 2007, pp. 901-907. doi:10.1016/j.jpowsour.2007.04.089

[6] X. K. Nonaqueous, "Liquid Electrolytes for Lithium-Based Rechargeable Batteries," Chemical Reviews, Vol. 104, No. 10, 2004, pp. 4303-4418. doi:10.1021/cr030203g

[7] K. Kubota, T. Nohira and R. Hagiwara, "New Inorganic Ionic Liquids Possessing Low Melting Temperatures and Wide Electrochemical Windows: Ternary Mixtures of Alkali Bis(Fluorosulfonyl)Amides," Electrochim Acta, Vol. 66, No. 1, 2012, pp. 320-324.

doi:10.1016/i.electacta.2012.01.097

[8] I. Masayuki, Y. Sachiko, K. Nao, et al., "Electrochemical 
Impedance of Electrolyte of Electrolyte/Electrode Interfaces of Lithium-Ion Rechargeable Batteries: Effects of Additives to the Electrolyte on Negative Electrode," Electrochim Acta, Vol. 51, No. 8-9, 2006, pp. 1629-1635.

[9] Smori, Hasahima and Hsuzukietal, "Chemical Properties of Various Organical Electrolytes for Lithium Rechargeablebatteries," Journal of Power Sources, Vol. 68, No. 1, 1997, pp. 59-64. doi:10.1016/S0378-7753(97)02619-0

[10] E. Peled, "The Electrochemical Behavior of Alkli and Alkaline Earth Metals in Nonaqueous Battery SystemsThe Solid Electrolyte Interphase," Journal of Electrochemistry Socity, Vol. 126, No. 12, 1979, pp. 2047-2051. doi:10.1149/1.2128859

[11] Y. Ein-Eli, B. Markovsky, D. Aurbach, et al., "The Dependence of the Performance of Li-C Intercalation Anodes $f$ or Li-Ion Secondary Batteries on the Electrolyte Solution Composition," Electrochimica Acta, Vol. 39, No. 17, 1994, pp. 2559-2569. doi:10.1016/0013-4686(94)00221-5

[12] A. Meitav and E. Peled, "Solid Electrolyte Interphase (SEI) Electrode Part V: The Formation and Properties of the Solid Electrolyte Interphase on Calcium in Thionyl-Chloride Solutions," Electrochimica Acta, Vol. 33, No. 8, 1988, pp. 1111-1121. doi:10.1016/0013-4686(88)80202-0

[13] G. Negasuramanian, P. E. Eled, A. I. Attia, et al., "Composite Solid Electrolyte for Li Battery Applications," Solid State Ionics, Vol. 67, No. 1-2, 1993, pp. 51-56. doi:10.1016/0167-2738(93)90308-P

[14] D. Aurbach and H. Gottlieb, "The Electrochemical Behavior of Selected Polar Aprotic Systems," Electrochimica Acta, Vol. 34, No. 2, 1989, pp. 141-156. doi:10.1016/0013-4686(89)87079-3

[15] R. J. Chen, F. Wu, L. Li, et al., "Butylene Sulfite as a FilmForming Additive to Propylene Carbonate-Based Electrolytes for Lithium Ion Batteries," Journal of Power Sources, Vol. 172, No. 1, 2007, pp. 395-403. doi:10.1016/i.jpowsour.2007.05.078

[16] H. Yoshitake, K. Abe, T. Kitakura, et al., "The Effect of Nano-Sized SEI Film Formed by Vinyl Acetate Additive for Li-Ion Batteries," Chemistry Letters, Vol. 32, No. 2, 2003, pp. 134-135. doi:10.1246/cl.2003.134

[17] F. Kito, S. Hideo, S. Sayaka, et al., "Characteristics of the Electrolyte with Fluoro Organic Lithium Salts," Journal of Power Sources, Vol. 90, No. 1, 2000, pp. 27-32. doi:10.1016/S0378-7753(00)00443-2

[18] P. Johansson and P. Jacobsson, "New Lithium Salts on the Computer: Fiction or Fact," Electrochimical Acta, Vol. 46, No. 10-11, 2001, pp. 1545-1552. doi:10.1016/S0013-4686(00)00751-9

[19] E. Peled, D. Golding, G. Ardel, et al., “Advanced Model for Solid Electrolyte Interphase Electrode in Liquid and Polymer Electrolytes," Journal of Electrochemical Society, Vol. 144, No. 8, 1997, pp. 208-210. doi:10.1149/1.1837858

[20] Z. X. Shu and R. S. McMillan, "Use of Chloroethylene Carbonate as Electrolyte Solvent for a Graphite Anode in a Lithium-Ion Battery," Journal of Electrochemical Society, Vol. 143, No. 7, 1996, pp. 2230-2235.

doi:10.1149/1.1836985
[21] K. Ome and T. Tan, "Non-Aqueous Electrolyte Solution and Its Use in Secondary Battery," 2000.

[22] A. Abouimrane, S. A. Odom, H. Tavassol, et al., "3-Hexylthiophene as a Stabilizing Additive for High Voltage Cathodes in Lithium-Ion Batteries," Journal of Electrochemical Society, Vol. 160, No. 2, 2013, pp. A268-A271.

[23] H. Tavassol, J. W. Buthker, L. A. Ferguson, et al., "Solvent Oligomerization during SEI Formation on Model Systems for Li-Ion Battery Anodes," Journal of Electrochemical Society, Vol. 159, No. 2, 2012, p. A730.

[24] D. Kam, K. Kim, et al., "Studies on Film Formation on Cathodes Using Pyrazole Derivatives as Electrolyte Additives in the Li-Ion Battery," Electrochemistry Communications, Vol. 11, No. 8, 1999, pp. 2230-2235. doi:10.1016/j.elecom.2009.06.020

[25] S. Y. Chen, Z. X. Wang, et al., "A Novel Flame Retardant and Film-Forming Electrolyte Additive for Lithium Ion Batteries," Journal of Power Sources, Vol. 187, No. 1, 2009, pp. 229-232. doi:10.1016/i.jpowsour.2008.10.091

[26] F. Wu, Q. Z. Zhu, L. Li, et al., "A Diisocyanate/Sufone Binary Electrolyte Based on Lithium Difluoro(Oxalate)Borate for Lithium Batteries," Journal of Material Chemistry A, Vol. 1, No. 11, 2013, pp. 3659-3666.

[27] G.-B. Han, R. Myuun-Hyun, K. Y. Cho, et al., "Effect of Succinic Anhydride as an Electrolyte Additive on Electrochemical Characteristics of Silicon Thin-Film Electrode," Journal of Power Sources, Vol. 195, No. 11, 2010, pp. 3709-3714. doi:10.1016/j.jpowsour.2009.11.142

[28] B. Simon and J. P. Boeuve, "Rechargeable Lithium Electrochemical Cell," US Patent 5626981, 1997.

[29] J. Barker and F. Gao, "Carbonaceous Electrode and Compatible Electrolyte Solvent," US Patent 5712059, 1998.

[30] Y. Naruse and S. Fujita, "Non-Aqueous Liuid Electrolyte Secondary Cell," US Patent 5714281, 1998.

[31] D. Aurbach, K. Gamolsky, B. Markovsky, et al., "On the Use of Vinylene Carbonate(VC) as an Additive to Electrolyte Solutions for Li-Ion Batteries," Electrchim Acta, Vol. 47, No. 9, 2002, pp. 1423-1439. doi:10.1016/S0013-4686(01)00858-1

[32] Z. X. Shu, R. S. Mcmillan, J. J. Murray, et al., "Use of Chloro Chylene Carbonate as an Electrolyte Solvent for a lithium Ion Batter Containing a Graphite Anode," Journal of Electrochimica Society, Vol. 142, No. 7, 1995, pp. L161L162.

[33] H. X. Xiao, B. C. Li, S. Wei, et al., "Gamma-Crotonlatione as an Electrolyte for Improving the Cyclability of MCMB Electrode," Journal of Power Sources, Vol. 174, No. 2, 2007, pp. 784-788. doi:10.1016/j.jpowsour.2007.06.148

[34] K. Xu, S. S. Zhang, T. R. Jow, et al., "LiBOB as Salt for Lithium-Ion Batteries: A Possible Solution for High Temperature Operation," Electrochem Solid-State Letters, Vol. 5, No. 1, 2002, pp. A26-A29. doi:10.1149/1.1426042

[35] U. Wietelmann, U. Lischka and M. Wegner, "Lithium Bisoxalatoborate, the Production Thereof and Its Use as a Conducting Salt," US Patent 6506516 B1, 2003.

[36] K. Xu, S. S. Zhang, B. A. Poese, et al., "Lithium Bis(Oxalato)Borate Stabilizes Graphite Anode in Propylene Car- 
bonate," Electrochem Solid-State Letters, Vol. 5, No. 11, 2002, pp. A259-A262. doi:10.1149/1.1510322

[37] S. Wang, W. H. Qiu, T. Li, et al., "Properties of Lithium LiBOB as a Lithium Salt and Cycle Performance in $\mathrm{LiMn}_{2} \mathrm{O}_{4}$ Half Cell," International Journal of Electrochem Science, Vol. 1, No. 1, 2006, pp. 250-257.

[38] X.-L. Tan, X.-Q. Cheng, Y.-L. Ma, et al., "Film Formation and Cycleability of LiBOB-Based Electrolyte," Acta Physico-Chimica Sinica, Vol. 25, No. 10, 2009, pp. 19671971.

[39] D. Aurbach, Y. E. Ely, O. Clusid, et al., "The Correlation between the Surface Chemistry and the Performance of LiCarbon Intercalation Anodes for Rechargeable 'RockingChair' Type Batteries," Journal of Electrochimica Society, Vol. 141, No. 3, 1994, pp. 603-611.

[40] T. Osaka, T. Momma and Y. Matsumoto, "Surface Charactierization of Electrodeposited Lithium Anode with En- haced Cycleability Obtained by $\mathrm{CO}_{2}$ Addition," Journal of Electrochemical Society, Vol. 144, No. 5, 1997, pp. 1709-1713. doi:10.1149/1.1837665

[41] J. O. Besenhard, M. Winter, J. Yang, et al., "Filming Mechanism of Lithium-Carbon Anodes in Organic and Inorganic Electrolytes," Journal of Power Sources, Vol. 54, NO. 2, 1995, pp. 3709-3714. doi:10.1016/0378-7753(94)02073-C

[42] S. Jee-Sun, H. Chi-Hwan, J. Un-Ho, et al., "Effect of $\mathrm{Li}_{2} \mathrm{CO}_{3}$ Additive on Gas Generation in Lithium-Ion Batteries," Power Sources, Vol. 109, No. 1, 2002, pp. 47-52. doi:10.1016/S0378-7753(02)00039-3

[43] H. H. Zheng, Y. B. Fu, H. C. Zhang, et al., "Potassium Salts: Electrolyte Additives for Enhancing Electrochemical Performances of Natural Graphite Anodes," Journal of Electrochemical Solid-State Letters, Vol. 9, No. 3, 2006, pp. A115-A119. doi:10.1149/1.2161447 